\title{
Elaboración de un hidrolizado de músculo desmenuzado de pota (Dosidicus gigas), con proteasa alcalina
}

\author{
Elaboration of a hydrolyzate of shredded muscle of pota \\ (Dosidicus igas), with alkaline protease
}

Juan R. Omote ${ }^{1}$; David Roldán ${ }^{2}$; Juan Juscamaita ${ }^{3}$

\begin{abstract}
Resumen
El presente trabajo de investigación realizado en el músculo desmenuzado de pota tuvo por finalidad evaluar el proceso de hidrólisis con proteasa alcalina. Se utilizó ejemplares provenientes del puerto de Talara y se sometieron a un estudio comparativo entre el nivel de hidrólisis del músculo crudo y cocido. Se determinó que la utilización de la alcalasa 2.4 L para obtener hidrolizados proteicos en base a músculo de pota fue factible, obteniéndose como parámetros adecuados para el proceso: temperatura de $60^{\circ} \mathrm{C}$, con un $\%(\mathrm{p} / \mathrm{v})$ de 0,7 y pH de $6-8$. Las características sensoriales del hidrolizado fue de un producto líquido de color blanco cremoso, no presentó olor ni sabor a pota y tampoco se detectó presencia de péptidos amargos. La composición química del hidrolizado fue: humedad 81,24 \%, proteína total 15,98 \%, ceniza 0,86 $\%$, grasa $0,48 \%$ y ELN 1,44 \%. La proteína soluble del hidrolizado final fue de 78,7 \% y se obtuvo un valor PER de 2,98 que corresponde a un producto de alta calidad proteica.
\end{abstract}

Palabras clave: pota; alcalasa 2.4L; proteína soluble; PER.

\begin{abstract}
The present research performed on the shredded muscle of pota, had as objective the evaluation of the hydrolysis process with alkaline protease. We used specimens from the port of Talara which were subjected to a comparative study between the level of hydrolysis of raw and cooked muscle. It was determined that the use of alcalasa $2.4 \mathrm{~L}$ to obtain protein hydrolyzates based on pota muscle was feasible, obtaining as suitable parameters for the process the following: temperature $60^{\circ} \mathrm{C}$, with $0.7 \% \mathrm{w} / \mathrm{v}$ and $\mathrm{pH}$ of $6-8$. The sensorial characteristics of the hydrolyzate product was a creamy white liquid, with no pota odor or flavor presented, and neither was detected the presence of bitter peptides. The chemical composition of the hydrolyzate was: $81.24 \%$ of moisture, total protein $15.98 \%$, ash $0.86 \%$, fat $0.48 \%$ and ELN $1.44 \%$. The soluble protein of the final hydrolyzate was $78.7 \%$, we obtained a PER value of 2.98 corresponding to a high-quality protein.
\end{abstract}

Keywords: pota; alcalasa $2.4 \mathrm{~L}$; soluble protein; PER.

\section{Introducción}

En el Perú, la pota o calamar gigante es uno de los principales productos de exportación no tradicional. Según la Comisión de Promoción para la Exportación y el Turismo (Prómpex, 2006), el volumen de exportación de pota se ha incrementado en forma notable en los últimos años debido a los bajos precios y a la gran variedad de presentaciones que impulsan una demanda internacional cada vez mayor. La industria de congelado del calamar gigante genera remanentes de carne que por las cualidades sensoriales y nutricionales que presenta, posibilitan su uso en la preparación de diversos productos procesados como son los derivados de músculo desmenuzado e hidrolizados concentrados de proteína.
Un hidrolizado proteico está formado por péptidos de diferentes tamaños originados de la hidrólisis de proteínas, catalizada por agentes químicos o por enzimas (Kristinsson y Rasco, 2000). Los hidrolizados proteicos de pescado han resultado útiles en la formulación de sustitutos parciales de leche y productos lácteos, como suplemento importante en la formulación de productos a base de cereales y sopas deshidratadas y se han incluido en el desarrollo de productos extruidos a base de almidón (Kristinsson y Rasco, 2000).

Una enzima es una proteína que actúa como catalizador biológico, llevando a cabo reacciones bioquímicas a muy altas velocidades; no se consume durante la reacción y en general presenta un elevado grado de especificidad. Todas

\footnotetext{
Universidad Nacional Agraria La Molina, Lima (Perú). Email: romote@lamolina.edu.pe

Universidad Nacional Agraria La Molina, Lima (Perú). Email: droldan@lamolina.edu.pe

Universidad Nacional Agraria La Molina, Lima (Perú). Email: jjm@lamolina.edu.pe
} 
las células, incluyendo microorganismos y organismos superiores, producen enzimas. Su estudio en el campo de los alimentos es de primordial interés debido a que son responsables de algunos cambios químicos que sufren los alimentos, cambios que pueden resultar beneficiosos (maduración de frutas) o perjudiciales (oxidación de ácidos grasos y oscurecimiento enzimático) (Badui, 2006).

Las propiedades de las enzimas derivan del hecho de ser proteínas y de actuar como catalizadores. Como proteínas, poseen una conformación natural más estable que las demás conformaciones posibles. Así, cambios en la conformación suelen ir asociados en cambios en la actividad catalítica. Los factores que influyen de manera más directa sobre la actividad de un enzima son: $\mathrm{pH}$, temperatura y presencia de coenzimas.

El presente estudio buscó evaluar el proceso de hidrólisis de músculo desmenuzado de pota (Dosidicus gigas), con proteasa alcalina. Los objetivos propuestos fueron: determinar los parámetros para elaborar un hidrolizado de músculo desmenuzado de pota, caracterizar el hidrolizado obtenido y determinar el valor de la relación de eficiencia proteica (PER), en el hidrolizado obtenido.

\section{Materiales y métodos}

\section{Lugar de ejecución}

El presente estudio de investigación se realizó en los laboratorios de Procesos y Microbiología Pesquera de la Facultad de Pesquería y el laboratorio de Biorremediación de la Facultad de Ciencias de la Universidad Nacional Agraria La Molina.

\section{Materia prima.}

Se utilizó manto de pota (Dosidicus gigas) adquirido en el Mercado Mayorista Pesquero del Callao, de MINKA, en estado fresco y refrigerado proveniente de la ciudad de Talara (Piura).

\section{Insumo.}

Enzima: alcalasa $2.4 \mathrm{~L}$

\section{Métodos de análisis.}

\section{Análisis sensorial.}

El grado de frescura del calamar gigante se evaluó siguiendo las recomendaciones de la tabla de análisis sensorial propuesto por Bravo (2001). El análisis sensorial del hidrolizado proteico de pota obtenida se realizó utilizando una tabla propuesta para la presente investigación teniendo en cuenta las características de color, olor, sabor y péptidos solubles.

\section{Composición química proximal.}

Los análisis fueron realizados en la materia prima y en el hidrolizado obtenido según procedimientos descritos por AOAC (2000).

\section{Otros análisis químicos para el hidrolizado}

Determinación de péptidos solubles: según procedimiento descrito por Peña (2008). Determinación de proteínas solubles, según el método de Lowry citado por Einsenthal y Danson (1992).

\section{Análisis microbiológico}

Realizados en el hidrolizado obtenido según las recomendaciones de Ingram, M., Bray, D. y Clark, D. (1980), las pruebas fueron: recuento de aerobios mesófilos, Staphylococcus aureus, coliformes, mohos y levaduras.

\section{Determinación de la relación de eficiencia proteica (PER)}

Se realizó en el hidrolizado obtenido de acuerdo al método de la AOAC (1990).

\section{Pruebas estadísticas}

Los resultados de los tratamientos experimentales fueron sometidos a la prueba estadística DCA (Diseño completamente al azar), con arreglo factorial, y la prueba de Tukey para comparar los tratamientos de la presente investigación. Todos los análisis se hicieron por medio del paquete estadístico SAS (1999).

\section{Parte Experimental}

La investigación fue realizada en tres etapas, en la primera etapa se evaluó el comportamiento de la alcalasa $0,5 \%(\mathrm{p} / \mathrm{v})$ en el proceso de hidrólisis a $60^{\circ} \mathrm{C}$ utilizando manto de pota molido cocido $\left(\mathrm{T}_{1}\right)$ y crudo $\left(\mathrm{T}_{2}\right)$, según recomendación de Novo Nordisk (1998). En la segunda etapa, se realizó la evaluación del comportamiento de la alcalasa en el proceso de hidrólisis utilizando diferentes cantidades de enzima y temperaturas. Los porcentajes de la enzima para los tratamientos $\left(\mathrm{T}_{3}, \mathrm{~T}_{4}\right.$ y $\left.\mathrm{T}_{5}\right)$ fueron $0,3,0,5$ y $0,7 \%$ en base al peso del manto molido. En la tercera etapa se evaluó el efecto del valor $\mathrm{pH}$ en el proceso de hidrólisis. Los valores de $\mathrm{pH}$ considerados para el experimento fueron 6,7 y 8 respectivamente (tratamientos $\mathrm{T}_{5}, \mathrm{~T}_{6} \mathrm{y}_{7}$ ). El procedimiento seguido se muestra en la Fig. 1.

Se recibió el manto de pota en cajas con hielo. Se tomó el peso y realizó el respectivo análisis sensorial para determinar el grado de frescura. El lavado se realizó utilizando una cremolada (agua/hielo entre 3 y $5^{\circ} \mathrm{C}$ ), con la finalidad de eliminar los restos de arena, contaminantes físicos y mantener el manto limpio a bajas temperaturas $\left(<5{ }^{\circ} \mathrm{C}\right)$. El manto limpio fue cortado en cubos de aproximadamente $2 \mathrm{~cm}$ de lado y posteriormente fueron lavados 3 veces cada uno por 10 minutos en cremolada, con la finalidad de eliminar el olor y sabor ácido del manto, según procedimiento recomendado por Lazo (2006). Después del lavado, el manto de pota fue molido utilizando un moledor de carne con criba de 5 milímetros de diámetro. Finalmente se mezcló el músculo de pota molida con la alcalasa. El proceso de hidrólisis se realizó en baño maría a diferentes temperaturas que fueron variables de estudio. Finalmente, el hidrolizado fue estabilizado a la temperatura de $90{ }^{\circ} \mathrm{C}$ por $15 \mathrm{~min}$ (Novo Nordisk, 1998) con la finalidad de inactivar la alcalasa. El hidrolizado obtenido fue evaluado tomando en cuenta las características sensoriales, contenido de péptidos solubles, análisis microbiológico y análisis químicos respectivos. 


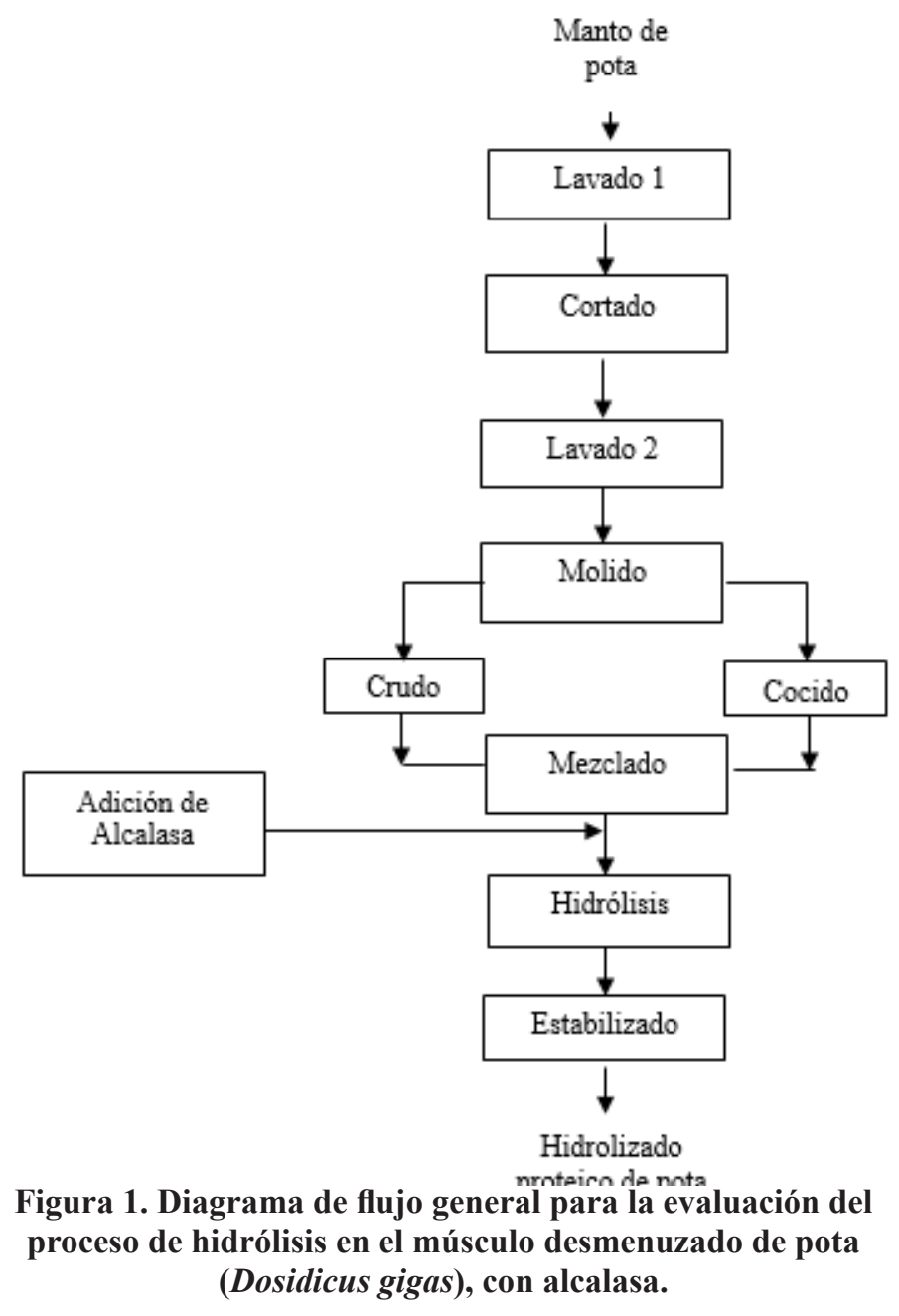

\section{Resultados y discusión}

\section{Materia prima}

\section{Análisis físico y sensorial}

El análisis sensorial de las unidades de pota realizado durante la investigación, reportó seis puntos de demérito. Dicho valor, según la Tabla utilizada, corresponde a una materia prima de excelente calidad. Bravo (2001) propone para un calamar gigante de óptima calidad un máximo 11,63 puntos de demérito.

\section{Composición química proximal}

Los resultados de la composición química proximal del manto del calamar gigante fueron: humedad 83,0 \%, proteína total $14,2 \%$, grasa cruda $1,4 \%$ y ceniza $1,0 \%$. Los valores de proteína, grasa y humedad fueron similares a los valores reportados por IMARPE/ITP (1996), Bravo (2001) y Lazo (2006). Las diferencias podrían atribuirse al grado de alimentación, época del año, madurez sexual, entre otros factores. Al respecto Sikorski (1994), reporta que las variaciones de la composición química podrían deberse a que como son animales acuáticos están influenciados por la época del año, sexo, madurez sexual, zona de captura y tamaño, entre otros.

\section{Parte experimental}

\section{Primera etapa}

La hidrólisis de las proteínas del manto del calamar gigante crudo y cocido generadas por la enzima alcalasa, en los tratamientos $\mathrm{T}_{1}$ (cocido) y $\mathrm{T}_{2}$ (crudo), se midió según el contenido de los péptidos solubles. Para ello, se utilizó la curva de calibración con peptona (Criterion Dehydrated Culture Media), a diferentes concentraciones, elaborada por Peña (2008) que permitió obtener la ecuación de una recta y el coeficiente de correlación siguiente:

Ecuación de la recta: $\mathrm{Y}=1,0268 \mathrm{X}+0,6058$

Coeficiente de correlación: $\mathrm{R}^{2}=0,9982$

Las lecturas reales de cantidad de peptonas obtenidos por el refractómetro en el proceso de hidrólisis de los tratamientos $\mathrm{T}_{1}$ y $\mathrm{T}_{2}$ se presentan en la Tabla 1.

En la Tabla 2 se reportan las unidades de péptidos solubles equivalentes a las lecturas del refractómetro.

Tabla 1. Lectura del refractómetro para los tratamientos T1 (cocido) y T2 (crudo)

\begin{tabular}{ccc}
\hline \multirow{2}{*}{ Tiempo (Horas) } & \multicolumn{2}{c}{ Enzima 0,5 \%p/v y } \\
& \multicolumn{2}{c}{ Temperatura $\mathbf{6 0}^{\circ} \mathbf{C}$} \\
& $\mathbf{T 1}$ & $\mathbf{T 2}$ \\
\hline 1 & 16,1 & 13,1 \\
2 & 17,1 & 13,9 \\
3 & 17,7 & 14,9 \\
4 & 19,3 & 15,1 \\
\hline
\end{tabular}


Tabla 2. Equivalencia de péptidos solubles según lectura de refractómetro para los tratamientos T1 (cocido) y T2 (crudo)

\begin{tabular}{ccc}
\hline & \multicolumn{2}{c}{ Enzima 0,5 \%p/v y Temperatura } \\
Tiempo (horas) & \multicolumn{2}{c}{$\mathbf{6 0}{ }^{\mathbf{C}} \mathbf{C}$} \\
& $\mathbf{T 1}$ & $\mathbf{T 2}$ \\
\hline 1 & 15,1 & 12,2 \\
2 & 16,1 & 13,0 \\
3 & 16,7 & 13,9 \\
4 & 18,6 & 14,1 \\
\hline
\end{tabular}

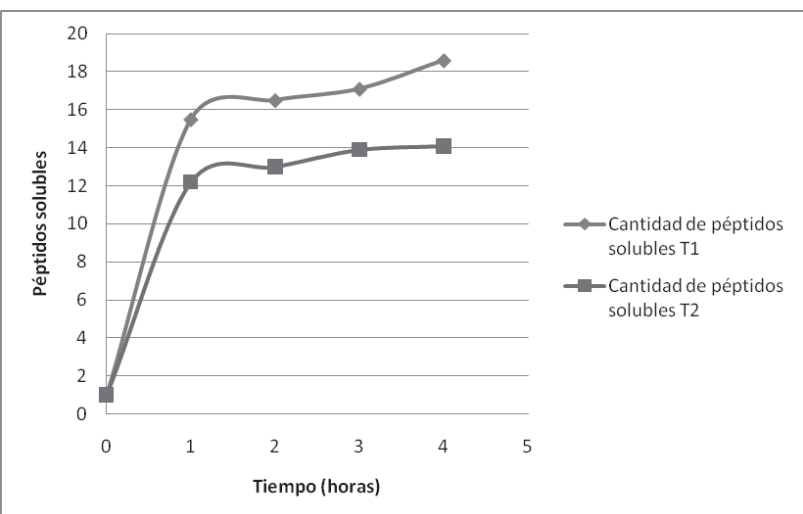

Figura 2. Comportamiento de los péptidos solubles a través del tiempo.
En la Tabla 2 se observa que los péptidos solubles del tratamiento $T_{1}$ llegaron a 18,6 en 4 horas de proceso mientras que en el tratamiento $\mathrm{T}_{2}$ se obtuvieron valores de 14,1 en el mismo periodo de tiempo. La diferencia obtenida en la hora 4 puede ser atribuida a que la enzima utilizada (alcalasa $0,5 \% \mathrm{p} / \mathrm{v}$ ) tenga mejor o mayor acción en proteínas desnaturalizadas por calor. Al respecto Novozymes (2002) menciona que la alcalasa es una enzima endoproteasa y que trabaja rompiendo las uniones péptidicas en el interior de las cadenas de polipéptidos. Por ello, es posible que la enzima utilizada tenga mejor o mayor acción en proteínas parcial o totalmente desnaturalizadas. Por otro lado, se conoce que el tratamiento térmico de la proteína (por ejemplo pasterización o calentamiento a $80-85{ }^{\circ} \mathrm{C}$ ), antes de la hidrólisis, desnaturalizará la proteína, haciéndola más accesible, y también ayudará a evitar la contaminación microbiana durante la hidrólisis

En la Fig. 2 se aprecia que los dos tratamientos tienen un comportamiento similar, en ambos casos se da una máxima pendiente entre las cero y una hora de hidrólisis en la cual se produce un incremento de los péptidos solubles de $82 \%$, a partir de ese punto se hace una distinción entre el $\mathrm{T}_{1}$ y el $\mathrm{T}_{2}$ en la cual el segundo tratamiento continua el incremento, pero en menor grado hasta llegar a una estabilidad a las 4 horas.

\section{Segunda Etapa}

Las lecturas del refractómetro durante el proceso de hidrólisis de los tratamientos $\mathrm{T}_{3}(0,3 \%) \mathrm{T}_{4}(0,5 \%)$ y

Tabla 3. Lectura de refractómetro para los tratamientos T3 $(0,3 \%), \mathrm{T} 4(0,5 \%), \mathrm{T} 5(0,7 \%)$ y A $\left(50^{\circ} \mathrm{C}\right), \mathrm{B}\left(60^{\circ} \mathrm{C}\right)$, $\mathrm{C}\left(\mathbf{7 0}^{\circ} \mathrm{C}\right)$

\begin{tabular}{|c|c|c|c|c|c|c|c|c|c|}
\hline \multirow{3}{*}{$\begin{array}{l}\text { Tiempo } \\
\text { (horas) }\end{array}$} & \multicolumn{3}{|c|}{$\mathrm{A}\left(50^{\circ} \mathrm{C}\right)$} & \multicolumn{3}{|c|}{$\mathrm{B}\left(60^{\circ} \mathrm{C}\right)$} & \multicolumn{3}{|c|}{$\mathrm{C}\left(\mathbf{7 0}^{\circ} \mathrm{C}\right)$} \\
\hline & \multicolumn{3}{|c|}{ Enzima \% p/v } & \multicolumn{3}{|c|}{ Enzima \% p/v } & \multicolumn{3}{|c|}{ Enzima \% p/v } \\
\hline & $\begin{array}{c}\mathbf{T}_{3} \\
(0,3 \%)\end{array}$ & $\begin{array}{c}\mathbf{T}_{4} \\
(0,5 \%)\end{array}$ & $\begin{array}{c}T_{5} \\
(0,7 \%)\end{array}$ & $T_{3}(0,3 \%)$ & $\begin{array}{c}\mathbf{T}_{4} \\
(0,5 \%)\end{array}$ & $\begin{array}{c}T_{5} \\
(0,7 \%)\end{array}$ & $\begin{array}{c}T_{3} \\
(0,3 \%)\end{array}$ & $\begin{array}{c}\mathbf{T}_{4} \\
(0,5 \%)\end{array}$ & $\begin{array}{c}T_{5} \\
(0,7 \%)\end{array}$ \\
\hline 1 & 10,9 & 12,3 & 13,0 & 13,2 & 14,8 & 14,6 & 12,5 & 12,1 & 12,2 \\
\hline 2 & 14,5 & 15,1 & 15,5 & 16,7 & 17,6 & 18,2 & 14,0 & 16,5 & 15,1 \\
\hline 3 & 16,1 & 16,6 & 16,6 & 17,8 & 18,4 & 19,3 & 15,2 & 16,8 & 16,0 \\
\hline 4 & 16,5 & 16,7 & 17,7 & 18,1 & 19,3 & 20,5 & 15,9 & 17,9 & 18,2 \\
\hline
\end{tabular}

Tabla 4. Equivalencia de péptidos solubles según lectura de refractómetro para los tratamientos T3 $(0,3 \%)$, T4 $(0,5 \%), \mathrm{T} 5(0,7 \%)$ y A $\left(50^{\circ} \mathrm{C}\right), \mathrm{B}\left(60^{\circ} \mathrm{C}\right), \mathrm{C}\left(70^{\circ} \mathrm{C}\right)$

\begin{tabular}{|c|c|c|c|c|c|c|c|c|c|}
\hline \multirow{3}{*}{$\begin{array}{l}\text { Tiempo } \\
\text { (horas) }\end{array}$} & \multicolumn{3}{|c|}{$\mathrm{A}\left(50^{\circ} \mathrm{C}\right)$} & \multicolumn{3}{|c|}{$\mathrm{B}\left(60^{\circ} \mathrm{C}\right)$} & \multicolumn{3}{|c|}{$\mathrm{C}\left(70^{\circ} \mathrm{C}\right)$} \\
\hline & \multicolumn{3}{|c|}{ Enzima \% p/v } & \multicolumn{3}{|c|}{ Enzima \% p/v } & \multicolumn{3}{|c|}{ Enzima \% p/v } \\
\hline & $\begin{array}{c}\mathbf{T}_{3} \\
(\mathbf{0 , 3} \%)\end{array}$ & $\begin{array}{c}T_{4} \\
(0,5 \%)\end{array}$ & $\begin{array}{c}T_{5} \\
(0,7 \%)\end{array}$ & $T_{3}(0,3 \%)$ & $\begin{array}{c}T_{4} \\
(0,5 \%)\end{array}$ & $\begin{array}{c}\mathbf{T}_{5} \\
(0,7 \%)\end{array}$ & $\begin{array}{c}\mathbf{T}_{3} \\
(0,3 \%)\end{array}$ & $\begin{array}{c}T_{4} \\
(0,5 \%)\end{array}$ & $\begin{array}{c}T_{5} \\
(0,7 \%)\end{array}$ \\
\hline 1 & 10,0 & 11,4 & 12,1 & 12,3 & 13,8 & 13,6 & 11,6 & 11,2 & 11,4 \\
\hline 2 & 13,5 & 14,1 & 14,5 & 15,7 & 16,6 & 17,1 & 13,2 & 13,6 & 14,7 \\
\hline 3 & 15,1 & 15,6 & 15,6 & 16,7 & 17,3 & 18,2 & 14,6 & 14,6 & 15,7 \\
\hline 4 & 15,4 & 15,6 & 16,7 & 17,1 & 18,2 & 19,4 & 14,7 & 15,6 & 16,0 \\
\hline
\end{tabular}


Tabla 5. Cálculo general del análisis de variancia (ANOVA) para determinar el coeficiente de variabilidad y el valor $\mathbf{F}$

\begin{tabular}{|c|c|c|c|c|c|}
\hline Fuente & Grados de libertad & Cuadrado medio & Valor $\mathbf{F}$ & $\operatorname{Pr}<\mathbf{F}$ & \\
\hline Modelo & 8 & 8,0917361 & 6,91 & $<0,0001$ & $* *$ \\
\hline Error & 27 & 1,2875926 & & & \\
\hline Total corregido & 35 & & & & \\
\hline
\end{tabular}

**Alta significancia coeficiente de variabilidad: 6,033969

$\mathrm{T}_{5}(0,7 \%)$ realizados a las temperaturas de $\mathrm{A}\left(50^{\circ} \mathrm{C}\right), \mathrm{B}$ $\left(60{ }^{\circ} \mathrm{C}\right)$ y $\mathrm{C}\left(70{ }^{\circ} \mathrm{C}\right)$ y las unidades de péptidos solubles equivalentes a las lecturas del refractómetro se reportan en las Tablas 3 y 4, respectivamente.

En la Tabla 4 se observa que a una misma temperatura $\left(50{ }^{\circ} \mathrm{C}, 60{ }^{\circ} \mathrm{C}\right.$ ó $\left.70{ }^{\circ} \mathrm{C}\right)$ la cantidad de péptidos solubles aumenta a medida que se incrementa la cantidad de enzima en el hidrolizado, sin embargo la mayor cantidad de péptidos solubles se alcanzó trabajando a $60{ }^{\circ} \mathrm{C}$ y 0,7 $\% \mathrm{p} / \mathrm{v}(19,4)$. Al parecer, las condiciones de $50{ }^{\circ} \mathrm{C}$ y 70 ${ }^{\circ} \mathrm{C}$ no permitieron el correcto trabajo de la enzima. Novo (1986) reporta que cuando se elige una temperatura de procesamiento para la enzima, se debe considerar qué es lo que se espera que haga; si se requiere solo un pequeño grado de hidrólisis, es posible alcanzarlo antes de la inactivación de la enzima. Para el proceso de hidrólisis se eligió trabajar con $60^{\circ} \mathrm{C}$, como temperatura óptima.

Según los análisis cuantitativos realizados por el paquete estadístico SAS, tratamientos $\mathrm{T}_{3}(0,3 \%), \mathrm{T}_{4}(0,5 \%), \mathrm{T}_{5}$ $(0,7 \%)$ realizados con $\mathrm{A}\left(50{ }^{\circ} \mathrm{C}\right), \mathrm{B}\left(60^{\circ} \mathrm{C}\right)$ y $\mathrm{C}\left(70^{\circ} \mathrm{C}\right)$ se presentan en la Tabla 5 , donde se puede observar que existe una alta significancia entre los tratamientos como son la cantidad de enzima y temperatura, mediante un DCA con arreglo factorial se determinó que existe una alta significancia entre los tratamientos estudiados.

En la Fig. 3 se muestra el comportamiento de la enzima a diferentes porcentajes (\%) y diferentes temperaturas.

El análisis de los resultados de los tratamientos y su interacción entre ellas, como la cantidad de enzima y

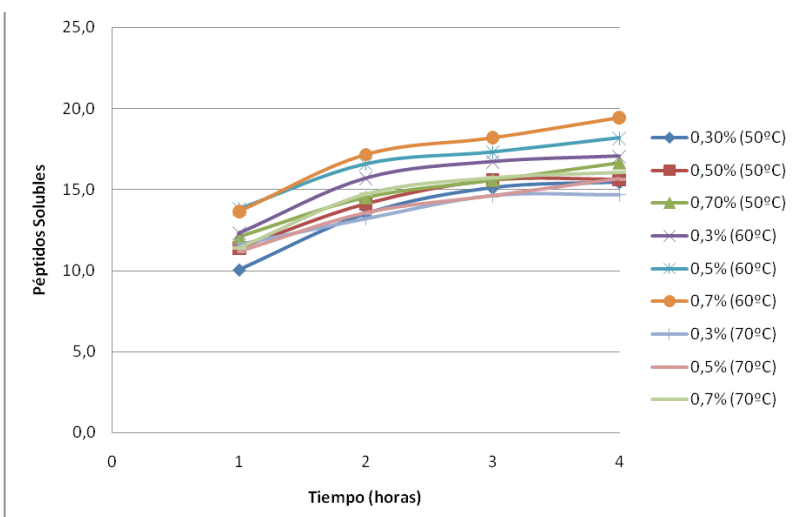

Figura 3. Comportamiento de la temperatura y enzima durante el proceso de hidrólisis en función de los péptidos solubles
Tabla 6. Lectura de refractómetro para los tratamientos T6 (pH 6), T7 (pH 7) y T8 (pH 8)

\begin{tabular}{|c|c|c|c|}
\hline \multirow[b]{2}{*}{$\begin{array}{l}\text { Tiempo } \\
\text { (horas) }\end{array}$} & \multicolumn{3}{|c|}{ Temperatura $60^{\circ} \mathrm{C}$} \\
\hline & $\mathrm{T}_{6}(\mathrm{pH} 6)$ & $\mathbf{T}_{7}(\mathbf{p H} 7)$ & $\mathrm{T}_{8}(\mathrm{pH} \mathrm{8})$ \\
\hline 1 & 14,4 & 14,0 & 13,9 \\
\hline 2 & 16,6 & 15,9 & 16,0 \\
\hline 3 & 18,3 & 17,7 & 18,1 \\
\hline 4 & 19,5 & 19,1 & 19,5 \\
\hline
\end{tabular}

Tabla 7. Equivalencia de péptidos solubles según lectura de refractómetro para los tratamientos T6 (pH 6), T7 (pH 7) y T8 (pH 8)

\begin{tabular}{cccc}
\hline & \multicolumn{3}{c}{ Temperatura $\mathbf{6 0}^{\circ} \mathbf{C}$} \\
$\begin{array}{c}\text { Tiempo } \\
\text { (horas) }\end{array}$ & $\mathbf{T}_{\mathbf{6}}$ (pH 6) & $\left.\mathbf{T}_{\mathbf{7}} \mathbf{( p H} 7\right)$ & $\mathbf{T}_{\mathbf{8}} \mathbf{( p H ~ 8 )}$ \\
\hline 1 & 12,9 & 13,0 & 13,4 \\
2 & 15,0 & 14,9 & 15,6 \\
3 & 17,0 & 16,6 & 17,2 \\
4 & 18,4 & 18,0 & 18,4 \\
\hline
\end{tabular}

la temperatura, evidenciaron una alta significancia, por lo que se realizó la prueba de Tukey para determinar el tratamiento más óptimo para el proceso de hidrólisis. El resultado obtenido indicó que el tratamiento $\mathrm{T}_{5}(0,7 \%$ de enzima) fue el más eficiente en comparación a los otros dos tratamientos.

\section{Tercera etapa}

Los resultados encontrados en el tercer experimento y las unidades de péptidos solubles equivalentes a las lecturas del refractómetro se reportan en las Tablas 6 y 7 , respectivamente.

Los resultados estadísticos presentados en la Tabla 8 no evidencian una significancia entre los tratamientos $\mathrm{T}_{6}, \mathrm{~T}_{7}$ y $\mathrm{T}_{8}$, por lo que el $\mathrm{pH}$ para el proceso de hidrólisis puede estar en el rango de 6 a 8 .

\section{Hidrolizado proteico del manto de pota}

\section{Análisis sensorial}

El hidrolizado proteico obtenido presentó una coloración blanca cremosa, no presentó olor característico del calamar gigante, la textura fue líquida con una concentración de péptidos solubles de 18,4; en cuanto al sabor, el hidrolizado obtenido no presentó ningún sabor 
Tabla 8. Cálculo del Diseño Completamente al Azar (DCA) para determinar el pH para la hidrólisis

\begin{tabular}{|c|c|c|c|c|c|}
\hline Fuente & Grados de libertad & Cuadrado medio & Valor F & $\operatorname{Pr}<\mathrm{F}$ & \\
\hline Modelo & 2 & 0,21333333 & 1,71 & 0,2340 & n.s. \\
\hline Error & 9 & 0,12444444 & & & \\
\hline Total corregido & 11 & & & & \\
\hline
\end{tabular}

Nota: n.s.: no significativo, coeficiente de variabilidad: 1.732079

característico a calamar gigante y tampoco se evidenció la presencia de péptidos amargos. Según la tabla de análisis sensorial para el hidrolizado de calamar gigante, el hidrolizado obtenido obtuvo una puntuación de 5 que corresponde a un producto de excelente calidad.

\section{Análisis químicos}

\section{Composición química proximal}

Los resultados de la composición química proximal realizado en el hidrolizado de manto del calamar gigante fueron: humedad $81,24 \%$, proteína total $15,98 \%$, grasa cruda $0,48 \%$ y ceniza $0,86 \%$.

Los valores de la composición química proximal del hidrolizado fueron muy similares a los obtenidos en la materia prima. La humedad del hidrolizado fue de 81,24 $\%$ y lo obtenido en el calamar gigante fresco fue 83,00 $\%$, la diferencia puede ser atribuida al acondicionamiento de la materia prima antes del proceso de hidrólisis, el proceso de cocción a $85^{\circ} \mathrm{C}$ por 10 minutos permitió una pérdida de humedad que se ve reflejada en el porcentaje de humedad del hidrolizado. El valor de la proteína de la pota también es ligeramente mayor $(15,98 \%)$ que el presentado por la materia prima $(12,60 \%)$, esta variación también puede ser atribuida al proceso de acondicionamiento de la materia prima antes del proceso de hidrólisis.

\section{Determinación de proteína soluble}

La proteína soluble del hidrolizado fue de 78,70\%, mientras que en la pota fresca es de 4,97 \% (Abugoch, L., Guarda, A. y Pérez, L., 2000). Según Lin y Park, (1996); Benjakull y Morrissey, (1997) y Jasra et al., (2001), citados por Belén, D., Moreno, M., García, D., Medina, C. y Sidorovas, A. (2007), este incremento se debe a los compuestos originados por el rompimiento de los enlaces peptídicos, lo cual produce péptidos de menor tamaño molecular en comparación con la proteína nativa, exponiendo los grupos amino y carboxilos ionizables de los aminoácidos que los conforman, favoreciendo la repulsión electrostática entre las moléculas e iones con un efecto neto de aumento de la hidrofilicidad y, por lo tanto, mayor solubilidad. Asimismo, Schwenke (1997) menciona que la hidrólisis parcial mejora la solubilidad de las proteínas.

\section{Análisis microbiológicos}

El hidrolizado proteico de manto de calamar gigante presentó $<1 \times 10$ ufc/g como recuento de aerobios viables; $<1 \times 10$ ufc/g en el recuento de Staphilococcus aureus; < 3 coliformes/g en el recuento de coliformes totales y < $1 \times 10 \mathrm{ufc} / \mathrm{g}$ en el recuento de mohos y levaduras.

Los resultados del recuento de aerobios mesófilos, mohos
Tabla 9. Tabla tentativa de análisis sensorial para el hidrolizado de calamar gigante (Dosidicus gigas)

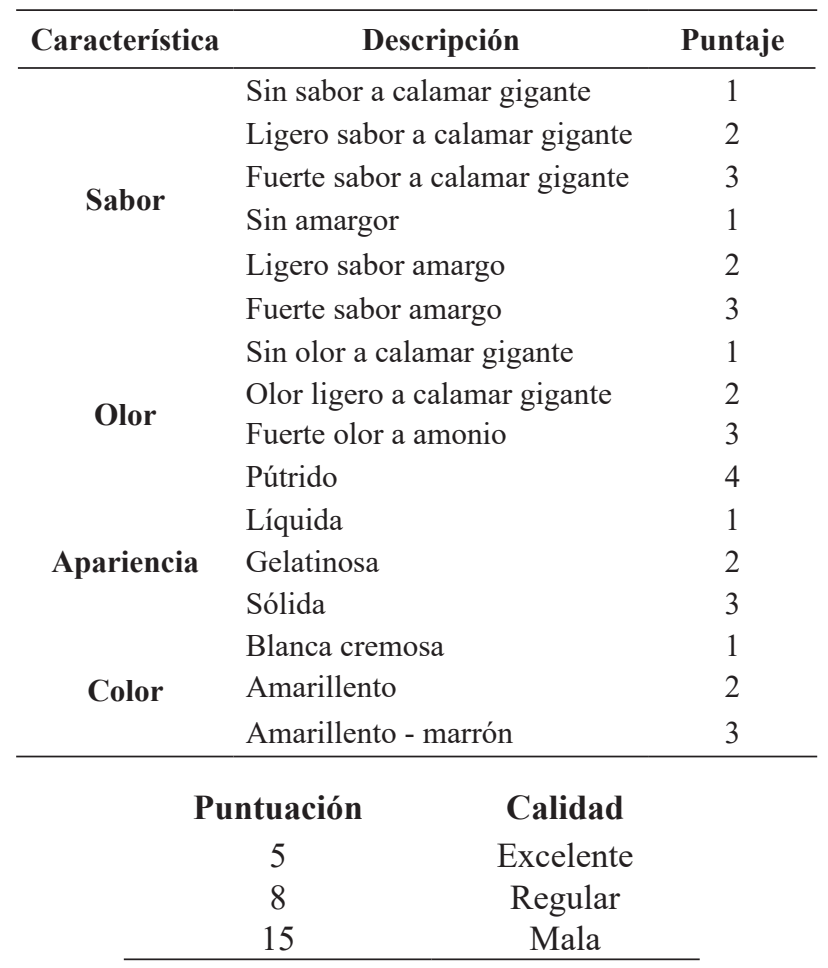

y levaduras se encuentran por debajo de los valores reportados por Chávez (1980) (aerobios mesófilos $\left(3,1 \times 10^{6} \mathrm{ufc} / \mathrm{g}\right)$, mohos y levaduras $\left.\left(0,5 \times 10^{2} \mathrm{ufc} / \mathrm{g}\right)\right)$ en su investigación sobre hidrolizado de pescado, valores que permitieron calificar al hidrolizado de pescado de buena calidad y de adecuada estabilidad microbiológica. Los resultados del recuento de Staphilococcus aureus, así como de coliformes totales, estuvieron por debajo de los valores mínimos estipulados para alimentos según MINSA (2012) (limite establecido de $10^{2} \mathrm{Ufc} / \mathrm{g}$ para Staphilococcus aureu y $10^{2}$ coliformes/g).

\section{Determinación de la relación de eficiencia proteica} (PER)

El PER calculado del hidrolizado fue de 2,98. Trabajos realizados sobre la evaluación del PER indican que valores superiores al PER de la caseína $(2,5)$ corresponden a proteínas de buena asimilación, de lo anterior se deduce que las proteínas del hidrolizado de manto de calamar gigante presentaría buena asimilación y por tanto una proteína que podría ser utilizada en alimentación humana.

\section{Rendimiento del proceso de hidrólisis}

El rendimiento final fue de 49,2 \%. El mayor porcentaje de disminución de peso fue en el proceso de cocción 
$(54,3 \%)$, resultado similar obtuvo Lazo (2006) en la etapa de precocción de elaboración de harina precocida de calamar gigante $(58,8 \%)$, lo que demuestra que esta especie pierde más del $40 \%$ de su peso durante esta etapa. Se debe tener en cuenta que la mayor fracción de este hidrolizado está constituida por agua $(81,24 \%)$, mientras que solo un $18,76 \%$ representa los sólidos provenientes de la materia prima.

Durante el desarrollo experimental se obtuvieron observaciones que permitieron elaborar un cuadro tentativo de análisis sensorial del hidrolizado de calamar gigante que se muestra en la Tabla 9.

\section{Conclusiones}

Se determinó que la utilización de la alcalasa $2.4 \mathrm{~L}$ para obtener hidrolizados proteicos en base a pota fue factible, obteniéndose como parámetros adecuados para el proceso: temperatura de $60^{\circ} \mathrm{C}$, con un $\%(\mathrm{p} / \mathrm{v})$ de $0,7 \mathrm{y}$ $\mathrm{pH}$ de 6-8. Las características sensoriales del hidrolizado fue de un producto líquido de color blanco cremoso, no presentó olor ni sabor a pota, y tampoco se detectó presencia de péptidos amargos. La composición química del hidrolizado fue de humedad $81,24 \%$, proteína total $15,98 \%$, ceniza $0,86 \%$, grasa $0,48 \%$ y ELN $1,44 \%$. La proteína soluble del hidrolizado final fue de 78,7\% y se obtuvo una valor PER de 2,98.

\section{Literatura ciada}

Abugoch, L.; Guarda, A. y Pérez, L. 2000. Caracterización funcional y bioquímica de la carne del manto de jibia (Dosidicus gigas). ALAN, 50 (4): 380-386. La asociación de las comunidades analíticas (AOAC). 2000. Oficial methods of analysis. Washintong D.C., USA: Association of Official Analytical Chemists. Inc.

Badui, S. 2006. Química de los alimentos. (4ta ed.). México: Editorial Pearson Prentice Hall.

Belén, D.; Moreno, M.; García, D.; Medina, C. y Sidorovas, A. 2007. Caracterización de un Hidrolizado Proteico Enzimático Obtenido del Pez Caribe Colorado (Pygocentrus cariba, Humboldt, 1821). INTERCIENCIA, 32 (3). Disponible en: http://www.interciencia.org/ v32_03/188.pdf

Bravo, V.2001. Desarrollo de una tabla de evaluación por análisis sensorial del calamar gigante o pota (Dosidicus gigas). Tesis (médico veterinario). Universidad Nacional Mayor de San Marcos, Lima.

Chávez, S. 1980. Elaboración de un Hidrolizado de Pescado por Método Químicos y Enzimático. Tesis (ing. pesquero). Universidad Nacional Agraria La Molina, Lima.
Comisión de Promoción del Perú para la Exportación y el Turismo (PRÓMPEX). 2006. Desenvolvimiento del comercio exterior pesquero 2006. Informe anual. Lima: Autor.

Ingram, M.; Bray, D. y Clark, D. 1980. Ecología Microbiana de los Alimentos. Factores que afectan a la supervivencia de los microorganismos en los alimentos. I.C.M.S.F. Tomo I, II. Zaragoza: Ed. Acribia.

Instituto del Mar del Perú (IMARPE) e Instituto Tecnológico Pesquero del Perú (ITP). 1996. Compendio Biológico Tecnológico de las Principales Especies Hidrobiológicas Comerciales del Perú. Lima: Ed. Stella.

Kristinsson, H. y Rasco, B. 2000. Biochemical and functional properties of Atlantic salmon (Salmo salar) muscle proteins hydrolyzed with various alkaline proteases. J. Agric. Food Chem., 48: 657-666.

Lazo, L. 2006. Elaboración de harina de pota (Dosidicus gigas) precocida para consumo humano. Tesis (ing. pesquero). Universidad Nacional Agraria La Molina, Lima.

MINSA. 2012. NTS $N^{\circ}-M I N S A / D I G E S A-V .01$ Norma Sanitaria que establece los criterios microbiológicos de calidad sanitaria e inocuidad para los alimentos y bebidas de consumo humano. Recuperado de

ftp://ftp2.minsa.gob.pe/normaslegales/2007/RM7092007.pdf

NOVO. 1986. NOVO's Handbook of Practical Biotechnology. Bagsvaerd, Denmark.

Novo Nordisk. 1998. Alcalase Food Grade. Recuperado de http://www.novo.dk

Peña, N. 2008. Utilización de Residuos de Pota (Dosidicus gigas), para la obtención de un fertilizante orgánico líquido. Tesis (ing. pesquero). Universidad Nacional Agraria La Molina, Lima.

SAS/STAT. 1999. User's guide. SAS Stargraphics (versión 8). Statistical Analysis System Institute. Cary, NC, USA.

Schwenke, K. 1997. Enzyme and chemical modification of proteins. En Srinivasan D. y Paraf, A. (Eds.) Food proteins and their applications. Dekker. Nueva York, EEUU.

Sikorski, Z. 1994. Tecnología de los Productos del Mar: Recursos, Composición nutritiva y Conservación. Zaragoza: Ed. Acribia S.A. 